\title{
Crescimento e Rendimento do Milho e da Braquiária em Sistema Consorciado com Diferentes Manejos de Plantas Daninhas ${ }^{1}$
}

\author{
Corn and Brachiaria Growth and Yield under Intercropping System with Different Weed \\ Managements
SILVA, P.I.B. ${ }^{2}$, FONTES, D.R. ${ }^{3}$, MORAES, H.M.F. ${ }^{3}$, GONÇALVES, V.A. ${ }^{3}$, SILVA, D.V. ${ }^{3}$, FERREIRA, L.R. ${ }^{3}$ e FELIPE, R.S. ${ }^{3}$

\begin{abstract}
RESUMO - Objetivou-se, neste trabalho, avaliar o crescimento e o rendimento do milho e da braquiária em monocultivos e consorciados, com diferentes manejos das plantas daninhas. O experimento foi realizado em área de pastagem degradada, num Latossolo Vermelho-Amarelo distrófico. Os tratamentos foram arranjados em esquema fatorial $4 \times 4+5$, sendo o primeiro fator correspondente aos cultivares de milho (UFV M100, DKB 390, DKB 455 e DKB 789) em consórcio com Urochloa brizantha, combinados com os diferentes manejos de plantas daninhas - capinado; sem controle de plantas daninhas; atrazine $\left(1,5 \mathrm{~kg} \mathrm{ha}^{-1}\right)$; e atrazine + nicosulfuron $\left(1,5 \mathrm{~kg} \mathrm{ha}^{-1}+8 \mathrm{~g} \mathrm{ha}^{-1}\right)-$, além dos monocultivos capinados de $U$. brizantha e dos quatro cultivares de milho. O delineamento experimental utilizado foi o de blocos casualizados com quatro repetições. Aos 30, 60, 90, 120 e 150 dias após o plantio (DAP), avaliou-se a matéria seca do milho e da braquiária; na última avaliação, determinou-se, também, o rendimento de grãos do milho. Os maiores acúmulos de matéria seca e rendimentos foram obtidos nos monocultivos da braquiária e do milho. No entanto, a aplicação de atrazine + nicosulfuron no consórcio proporcionou rendimento de grãos de milho similar ao obtido no monocultivo. Os efeitos dos manejos das plantas daninhas e dos cultivares de milho no crescimento da braquiária somente se manifestaram nas avaliações realizadas aos 90, 120 e 150 DAP. Os híbridos de milho mostraram-se mais competitivos com a braquiária do que a variedade; o maior rendimento de grãos foi obtido com o híbrido simples (DKB 390), e o menor, com o híbrido triplo (DKB 455). A interferência de U. brizantha no milho, quando cultivados em consórcio, depende das práticas de manejo de plantas daninhas e do cultivar de milho adotado.
\end{abstract}

Palavras-chave: Zea mays, Urochloa brizantha, plantio direto, herbicida.

\begin{abstract}
The objective of this study was to evaluate the growth and yield of maize and brachiaria mono- and inter-cropping systems with different weed managements. The experiment was conducted in a degraded pasture area in a dystrophic Oxisol. Treatments were arranged in a factorial $4 \times 4+5$, with the first factor corresponding to maize cultivars (UFV M100, DKB 390, DKB 455, and DKB 789) in consortium with Urochloa Brizantha, with different weed managements (weeded; no weed control; atrazine $\left(1.5 \mathrm{~kg} \mathrm{ha}^{-1}\right)$ and atrazine + nicosulfuron $\left(1.5 \mathrm{~kg} \mathrm{ha}^{-1}+8 \mathrm{~g} \mathrm{ha} \mathrm{g}^{-1}\right)$, in addition to $\boldsymbol{U}$. brizantha weeded monocultures and four maize cultivars. The experimental design was a randomized block with four replications. At 30, 60, 90, 120, and 150 days after planting (DAP), maize dry matter and brachiaria dry matter were evaluated, with the last evaluation was determining maize grain yield. Higher dry matter accumulation and yields were obtained using maize and brachiaria monocultures. However, the application of atrazine + nicosulfuron in consortium produced maize grain yield similar to that obtained in monoculture. The effects of weed and maize cultivar managements on brachiaria growth were only manifested in the assessments at 90, 120 and 150 DAP. The maize hybrids were found to be more competitive with brachiaria than the variety; the highest grain yield was obtained with the simple hybrid (DKB 390) and the lowest with the triple hybrid (DKB 455). The interference of $\boldsymbol{U}$. brizantha in maize depends on the management of the weed practices adopted.
\end{abstract}

Keywords: Zea mays, Urochloa brizantha, no-tillage system, herbicide.

1 Recebido para publicação em 5.9.2013 e aprovado em 6.11.2013.

2 Universidade Federal Rural do Semiárido, Mossoró-RN, Brasil, <pauloigor@ufv.br>. ${ }^{3}$ Universidade Federal de Viçosa, Viçosa-MG, Brasil. 


\section{INTRODUÇÃO}

As pastagens naturais da Zona da Mata, mesorregião do Estado de Minas Gerais formada por 142 municipios, apresentam solos com elevada acidez, baixa fertilidade natural (Vitor et al., 2008) e elevados teores de alumínio e encontram-se degradadas (Mesquita et al., 2004; Vitor et al., 2008), em maior ou menor grau (Nascimento et al., 2006).

A recuperação e/ou renovação de pastagens são estratégias para melhoria da produção e cobertura vegetal em áreas degradadas. A renovação das pastagens na Zona da Mata tem sido a alternativa preferida pelos produtores (Vitor et al., 2008). Contudo, como o relevo predominante nessa região é acidentado, o preparo do solo é difícil e desaconselhável, o que torna o sistema de plantio direto uma alternativa mais adequada para recuperação de pastagem. Esse sistema tem como características principais a preservação dos atributos físicos do solo (Pierce et al., 1994), proteção física da matéria orgânica (Bayer et al., 2000), adição à eliminação de custos adicionais com arações e gradagens (Ciotta et al., 2004) e redução da intensidade de infestação das plantas daninhas (Jakelaitis et al., 2005).

Devido aos altos investimentos necessários para a formação, recuperação e reforma de pastagens, têm-se buscado técnicas que visam à diminuição desses custos. Entre essas técnicas, a consorciação de culturas com forrageiras tem sido preconizada na formação e reforma de pastagens, produção de forragem para confinamento, bem como na cobertura morta para plantio direto das culturas (Jakelaitis et al., 2006). Além disso, os nutrientes utilizados para adubar a cultura retornam ao solo parcialmente, através do processo de ciclagem, e podem ser úteis à forrageira. Em consórcio com forrageiras, especialmente Urochloa spp., várias culturas têm sido empregadas, porém o milho tem sido a preferida devido à sua tradição de cultivo, ao grande número de cultivares comerciais adaptados a diferentes regiões ecológicas do Brasil e à excelente adaptação, quando manejado em consórcio (Jakelaitis et al., 2005). Todavia, os efeitos decorrentes da interferência negativa das plantas daninhas podem inviabilizar a consorciação milho-braquiária, por meio dos prejuízos que podem ocorrer no estabelecimento da forrageira consorciada e no rendimento de grãos da cultura. Dessa maneira, tem-se preconizado o uso de subdoses de herbicidas para controle das infestantes e redução do potencial competitivo da braquiária (Freitas et al., 2008).

A avaliação do crescimento das culturas, embora trabalhosa, tem implicações teóricas e práticas. Essa avaliação permite a obtenção de informações que possibilitam entender melhor o desempenho das culturas. Nesse sentido, objetivou-se avaliar o crescimento e o rendimento de quatro cultivares de milho e Urochloa brizantha (cv. Marandu), em monocultivos e consorciados, com diferentes manejos das plantas daninhas.

\section{MATERIAL E MÉTODOS}

O experimento foi realizado no município de Cajuri-MG (altitude de $679 \mathrm{~m}$; latitude de $20^{\circ} 46^{\prime} 19^{\prime \prime} \mathrm{S}$ e longitude de 42 46' 20" W) em área de pastagem degradada, num Latossolo Vermelho-Amarelo distrófico de textura argilosa e de baixa fertilidade (Tabela 1). O clima da região é Cwa, isto é, subtropical úmido com inverno seco e verão quente, de acordo com a classificação de Köppen-Geiger, com temperatura média anual de $19^{\circ} \mathrm{C}$ e precipitação média anual de $1.200 \mathrm{~mm}$. Os indices pluviométricos e as temperaturas médias ocorridas durante o período experimental são apresentados na Figura 1.

O delineamento experimental utilizado foi o de blocos casualizados com quatro repetições. Os tratamentos foram arranjados em esquema fatorial $4 \times 4+5$, sendo o primeiro fator correspondente aos cultivares de milho (variedade de polinização-livre - UFV M100; híbrido simples - DKB 390; híbrido triplo - DKB 455; e híbrido duplo - DKB 789) em consórcio com Urochloa brizantha, combinados com os diferentes sistemas de controle de plantas daninhas (capinado, sem controle de plantas daninhas, aplicação de $1,5 \mathrm{~kg} \mathrm{ha}^{-1}$ de atrazine e aplicação de $1,5 \mathrm{~kg} \mathrm{ha}^{-1}$ de atrazine $+8 \mathrm{~g} \mathrm{ha}^{-1}$ de nicosulfuron), além do monocultivo capinado de $U$. brizantha e dos quatro cultivares de milho.

Aos 60 dias antes do plantio, realizou-se uma roçada e a aplicação a lanço e sem 
Tabela 1 - Características químicas e físicas do solo da área experimental ${ }^{\underline{1}}$

\begin{tabular}{|c|c|c|c|c|c|c|c|c|c|}
\hline $\mathrm{pH}$ & $\mathrm{P}^{1 / /}$ & $\mathrm{K}^{2}$ & $\left(\mathrm{Ca}^{2+}\right)^{3}$ & $\left(\mathrm{Mg}^{2+}\right)^{3}$ & $\mathrm{Al}^{3+}$ & $\mathrm{H}+\mathrm{Al}$ & SB & $\mathrm{t}$ & $\mathrm{T}$ \\
\hline$\left(\mathrm{H}_{2} \mathrm{O}\right)$ & \multicolumn{2}{|c|}{$\left(\mathrm{mg} \mathrm{dm}^{-3}\right)$} & \multicolumn{7}{|c|}{$\left(\mathrm{cmol}_{\mathrm{c}} \mathrm{dm}^{-3}\right)$} \\
\hline 4.4 & 1,9 & 14,0 & 0,20 & 0,1 & 1,80 & 8,75 & 0,34 & 2,14 & 9,09 \\
\hline $\mathrm{m}$ & V & $\mathrm{MO}^{\underline{1} /}$ & $\mathrm{S}$ & $\mathrm{Zn}$ & $\mathrm{Fe}$ & $\mathrm{Mn}$ & $\mathrm{Cu}$ & \multicolumn{2}{|c|}{ Prem } \\
\hline \multicolumn{2}{|c|}{$(\%)$} & $\left(\right.$ dag kg $\left.{ }^{-1}\right)$ & \multicolumn{5}{|c|}{$\left(\mathrm{mg} \mathrm{dm}^{-3}\right)$} & \multicolumn{2}{|c|}{$\left(\mathrm{mgL}^{-1}\right)$} \\
\hline 84,0 & 4,0 & 2,10 & - & 0,70 & 83,0 & 5,60 & 0,20 & \multicolumn{2}{|c|}{12,20} \\
\hline \multicolumn{2}{|c|}{ Textura $(\%)$} & \multicolumn{2}{|c|}{ Argila: 58} & \multicolumn{3}{|c|}{ Silte: 9} & \multicolumn{3}{|c|}{ Areia: 33} \\
\hline
\end{tabular}

1/Análise realizada pelo Laboratório de Análise de Solo do Departamento de Solos da Universidade Federal de Viçosa.

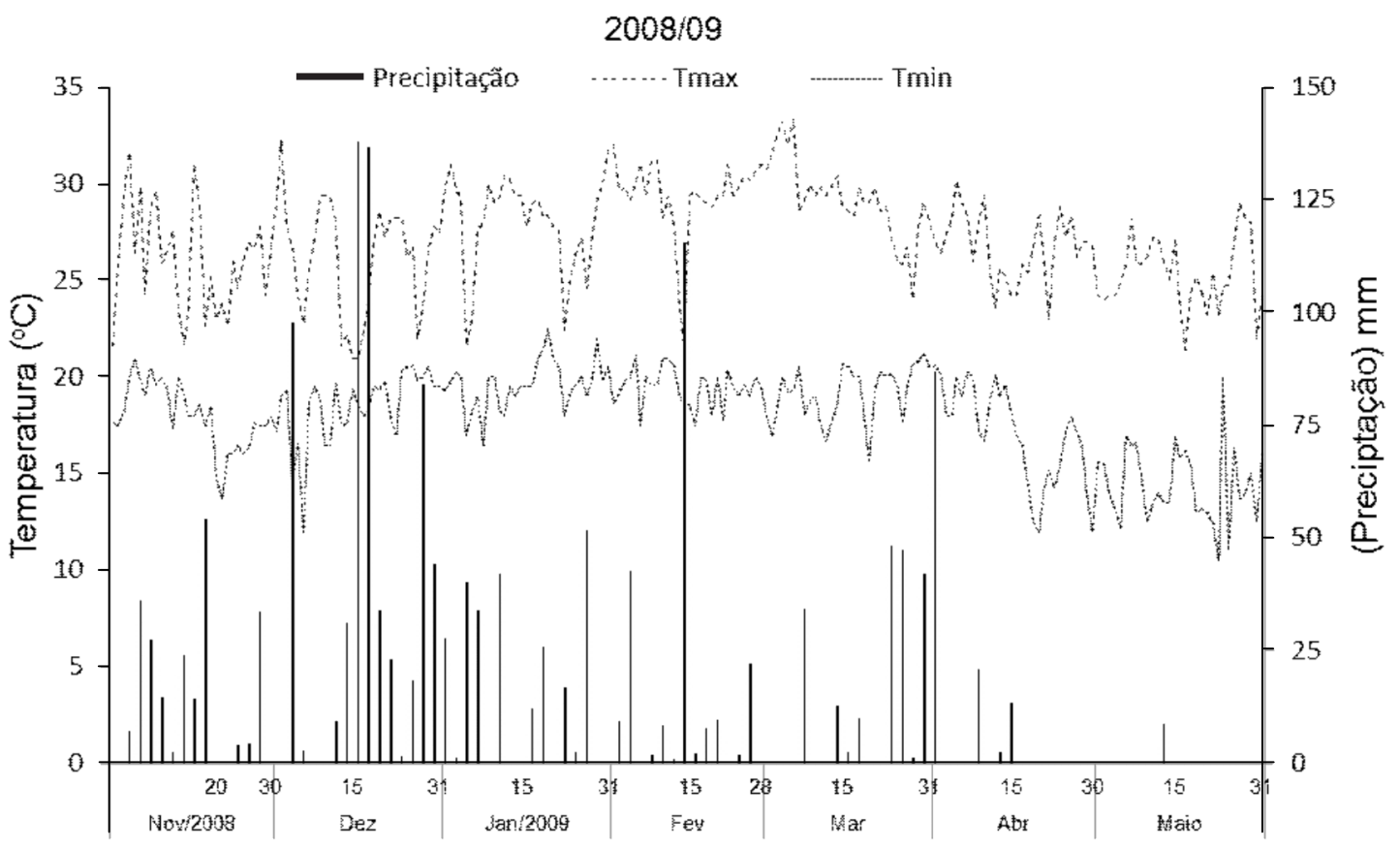

Figura 1 - Dados de precipitação pluvial e temperaturas máxima e mínima do ar em Cajuri-MG durante o período experimental $(2008 / 2009)$.

incorporação de 3,0 t. ha ${ }^{-1}$ de agrossilício, visando à correção da acidez do solo. A dessecação foi feita 20 dias antes do plantio, com a aplicação de $1,8 \mathrm{~kg} \mathrm{ha}^{-1}$ de glifosato e 0,67 kg ha-1 de 2,4-D.

O plantio simultâneo do milho e da braquiária foi feito em 20/11/2008, utilizando-se a semeadora de plantio direto Semeato SHM11/13. O milho foi plantado no espaçamento de 0,6 m entre fileiras de plantas, com densidade de plantio de 65.000 plantas ha-1. Nos consórcios, a braquiária foi semeada na linha de semeadura do milho, na profundidade de $2,0 \mathrm{~cm}$, usando-se $5 \mathrm{~kg} \mathrm{ha}^{-1}$ de sementes, com valor cultural de $76 \%$. A adubação de plantio foi realizada com $500 \mathrm{~kg} \mathrm{ha}^{-1}$ da fórmula NPK 08-24-12. Na adubação de cobertura, foram aplicados $500 \mathrm{~kg} \mathrm{ha}^{-1}$ de 30-00-10 aos 45 dias após o plantio. A unidade experimental foi constituída de oito fileiras de milho, com $5 \mathrm{~m}$ de comprimento, no espaçamento de $0,6 \mathrm{~m}$ entre fileiras das duas culturas. As avaliações foram realizadas nos $3,0 \mathrm{~m}$ centrais das seis linhas centrais, em área de $10,8 \mathrm{~m}^{2}$ por parcela.

A capina e a aplicação dos herbicidas foram realizadas aos 30 dias após plantio (DAP). Os herbicidas foram aplicados nas plantas 
de braquiária com dois a três perfilhos com auxílio de pulverizador costal com válvula reguladora, visando manter a pressão constante de 2 bar, sendo a barra equipada com dois bicos TT 110.02, espaçados de $1,0 \mathrm{~m}$, calibrado para aplicar o equivalente a $100 \mathrm{~L} \mathrm{ha}^{-1}$ de calda. No momento da aplicação dos herbicidas o solo encontrava-se úmido e a velocidade do vento era em torno de $5 \mathrm{~km} \mathrm{~h}^{-1}$, com temperatura em torno de $25{ }^{\circ} \mathrm{C}$ e umidade relativa de aproximadamente $80 \%$.

Aos 30, 60, 90, 120 e 150 DAP, foi avaliada a matéria seca do milho e da braquiária. Para o milho, coletaram-se cinco plantas ao acaso na área útil das parcelas, e para a braquiária, avaliaram-se as plantas presentes em 1,0 m de fileira. Em cada época de amostragem, as plantas foram cortadas rente ao solo e colocadas em estufa de circulação forçada de ar, regulada à temperatura de $\pm 70{ }^{\circ} \mathrm{C}$, por 72 horas. Aos 150 DAP, realizou-se a determinação da altura das plantas e do rendimento de grãos do milho e de matéria seca da braquiária.

Os dados foram submetidos à análise de variância, e as médias, comparadas pelo teste de Tukey a 5\% de probabilidade. Para análise dos efeitos de épocas de amostragem, os dados foram analisados como os de um experimento com parcelas subdivididas no tempo. O crescimento (y) das duas culturas, em função do tempo $(\mathrm{t})$, foi descrito por equações sigmoidais logisticas do tipo $y=\alpha /\left(1+\beta \mathrm{e}^{-} \gamma \mathrm{t}\right)$, em que $\alpha, \beta$ e $\gamma$ são os parâmetros da equação. As equações de regressão foram ajustadas usando-se o software Table Curve (Scientific, 1991).

\section{RESULTADOS E DISCUSSÃO}

Considerando o crescimento da braquiária, constatou-se efeito significativo de cultivares de milho $(\mathrm{C})$, manejo de plantas daninhas $(\mathrm{M})$, épocas de avaliação do crescimento (E) e das interações $\mathrm{M} \times \mathrm{E}$ e $\mathrm{M}$ x C. A matéria seca da braquiária avaliada aos 30 e 60 dias após o plantio (DAP) não se diferenciou em virtude dos manejos das plantas daninhas (Tabela 2). Contudo, aos 90 DAP, a braquiária em monocultivo e nas parcelas onde as demais plantas daninhas foram capinadas apresentou maior acúmulo de matéria seca em relação aos demais métodos de controle. Observa-se, também, que na presença das plantas daninhas

Tabela 2 - Matéria seca da parte aérea da braquiária em diferentes sistemas de cultivo e épocas de avaliação

\begin{tabular}{|c|c|c|c|c|c|}
\hline \multirow{5}{*}{$\begin{array}{l}\text { Época de coleta } \\
\text { (dias após o plantio) }\end{array}$} & \multicolumn{5}{|c|}{ Sistemas de cultivo } \\
\hline & \multirow[b]{3}{*}{$\begin{array}{l}\text { Braquiária em } \\
\text { monocultivo, com } \\
\text { capinas }\end{array}$} & \multicolumn{4}{|c|}{ Braquiária em consorciação com milho } \\
\hline & & \multicolumn{4}{|c|}{ Manejo de plantas daninhas } \\
\hline & & Com capinas & $\begin{array}{c}\text { Atrazine } \\
\left(1,5 \mathrm{~kg} \mathrm{ha}^{-1}\right)\end{array}$ & $\begin{array}{l}\text { Sem controle de } \\
\text { plantas daninhas }\end{array}$ & $\begin{array}{c}\text { Atrazine }+ \\
\text { nicosulfuron } \\
\left(1,5 \mathrm{~kg} \mathrm{ha}^{-1}+\right. \\
\left.8 \mathrm{~g} \mathrm{ha}^{-1}\right)\end{array}$ \\
\hline & \multicolumn{5}{|c|}{ Matéria seca da parte aérea $\left(\mathrm{y}, \mathrm{kg} \mathrm{ha}^{-1}\right)$} \\
\hline 30 & $8 \mathrm{~A}^{\underline{1}}$ & $14 \mathrm{~A}$ & $10 \mathrm{~A}$ & $7 \mathrm{~A}$ & $6 \mathrm{~A}$ \\
\hline 60 & $583 \mathrm{~A}$ & $712 \mathrm{~A}$ & $525 \mathrm{~A}$ & $352 \mathrm{~A}$ & $143 \mathrm{~A}$ \\
\hline 90 & $3.979 \mathrm{~A}$ & $3.666 \mathrm{~A}$ & $2.955 \mathrm{~B}$ & $2.068 \mathrm{C}$ & $694 \mathrm{D}$ \\
\hline 120 & $6.704 \mathrm{~A}$ & $5.984 \mathrm{~B}$ & $5.143 \mathrm{C}$ & $4.024 \mathrm{D}$ & $1.889 \mathrm{E}$ \\
\hline 150 & $8.130 \mathrm{~A}$ & $6.755 \mathrm{~B}$ & $6.692 \mathrm{~B}$ & $5.550 \mathrm{C}$ & $3.686 \mathrm{D}$ \\
\hline \multicolumn{6}{|c|}{ Equações de regressão e respectivos coeficientes de determinação } \\
\hline \multicolumn{3}{|c|}{ Braquiária em monocultivo - com capinas } & \multicolumn{3}{|c|}{$\mathrm{y}=8313,5 /\left(1+141,2 \mathrm{e}^{24,9 t}\right), \mathrm{R}^{2}=0,96$} \\
\hline \multicolumn{3}{|c|}{ Braquiária em consorciação - com capinas } & \multicolumn{3}{|c|}{$\mathrm{y}=7753,5 /\left(1+145,1 \mathrm{e}^{26,5 t}\right), \mathrm{R}^{2}=0,96$} \\
\hline \multicolumn{3}{|c|}{ Braquiária em consorciação - atrazine } & \multicolumn{3}{|c|}{$\mathrm{y}=6708,3 /\left(1+145,1 \mathrm{e}^{25,6 t}\right), \mathrm{R}^{2}=0,97$} \\
\hline \multicolumn{3}{|c|}{ Braquiária em consorciação - sem controle de daninhas } & \multicolumn{3}{|c|}{$\mathrm{y}=5541,4 /\left(1+147,5 \mathrm{e}^{24,7 t}\right), \mathrm{R}^{2}=0,98$} \\
\hline \multicolumn{3}{|c|}{ Braquiária em consorciação - atrazine + nicosulfuron } & \multicolumn{3}{|c|}{$\mathrm{y}=3490,4 /\left(1+162,1 \mathrm{e}^{23,2 \mathrm{t}}\right), \mathrm{R}^{2}=0,99$} \\
\hline \multicolumn{6}{|c|}{ Coeficiente de variação experimental $(\mathrm{CV})_{\text {parcelas }}=11,9 \% ; \mathrm{CV}_{\text {subparcelas }}=53,4 \%$} \\
\hline
\end{tabular}

Planta Daninha, Viçosa-MG, v. 32, n. 2, p. 301-309, 2014 
(tratamento sem controle) o acúmulo de matéria seca foi menor, em razão da competição com as plantas infestantes e com a cultura do milho. Carvalho et al. (2011) relataram que a competição com o milho reduziu em 33\% o acúmulo de matéria seca da braquiária.

$\mathrm{Na}$ avaliação final, realizada aos 150 DAP, observou-se redução do acúmulo da matéria seca em todos os consórcios, quando comparado ao monocultivo (Tabela 2). No consórcio de $U$. brizantha com milho, Portes et al. (2000) verificaram que o sombreamento exercido pelo milho afetou negativamente o crescimento, o perfilhamento e o rendimento forrageiro de $U$. brizantha até a colheita da cultura. Resultados semelhantes também foram observados por Jakelaitis et al. (2005) para $U$. decumbens.

A aplicação de atrazine + nicosulfuron mostrou-se eficiente para reduzir o crescimento da braquiária (Tabela 2). Segundo Jakelaitis et al. (2005), o nicosulfuron em subdoses reduz o crescimento da forrageira, permitindo o desenvolvimento e, consequentemente, a produção satisfatória de grãos de milho. Entretanto, essa diminuição do crescimento de braquiária é temporária, como pode ser observado pelo incremento de $95 \%$ da matéria seca acumulada entre as duas últimas avaliações (120 e 150 DAP) (Tabela 2). $\mathrm{O}$ nicosulfuron, pertencente ao grupo químico das sulfonilureias, atua sobre a acetolactato sintase, que catalisa a primeira reação na biossíntese de aminoácidos ramificados, valina, leucina e isoleucina, provocando a interrupção da síntese de proteínas e consequente inibição da divisão celular e crescimento da planta (Anderson et al., 1998).

Não foi constatada diferença entre os cultivares de milho no acúmulo de matéria seca da braquiária até os 90 DAP (Tabela 3). Entretanto, após essa época, observaram-se menores acúmulos de matéria seca do crescimento da braquiária em competição com os híbridos de milho. O híbrido simples DKB 390 possui ciclo precoce, diferentemente da variedade UFV M100, de ciclo semiprecoce. É possivel que, pelo fato de a variedade possuir ciclo mais longo, sua germinação e emergência ocorram de forma mais lenta, expondo a cultura ao sombreamento e à maior interferência imposta pelas plantas infestantes e de braquiária (Carvalho et al., 2011). Freitas et al. (2008) também relataram que a variedade UFV M100 foi a mais sensivel à competição com a braquiária, recomendando, nesse caso, a aplicação de herbicidas do grupo da sulfonilureias.

Segundo Chikoye et al. (2008), existem diferenças entre os cultivares de milho quanto à sua habilidade competitiva. Essas diferenças estão relacionadas às características do sistema radicular e da parte aérea de cada genótipo. Como o crescimento do milho é maior do que o da braquiária nos primeiros dias após o plantio, as características da parte aérea tornam-se mais importantes, pois estarão diretamente relacionadas com o tempo de cobertura do solo e supressão das plantas competidoras (Paciullo et al., 2011). A altura de planta da variedade UFV M100 e do híbrido simples DKB 390 foi maior do que a observada para o híbrido triplo DKB 455, mas não interferiu no acúmulo de matéria seca da braquiária (Tabela 2), indicando que, nesse caso, a arquitetura das plantas talvez seja o fator mais importante para a capacidade competitiva.

Considerando o rendimento de forragem da braquiária, observou-se efeito de cultivar de milho $(\mathrm{C})$, de manejo de controle de plantas daninhas $(\mathrm{M})$ e da interação $\mathrm{C} \times \mathrm{M}$. O monocultivo da braquiária proporcionou maior rendimento de forragem que os consórcios (Tabela 4). De maneira geral, na comparação entre o rendimento da forrageira em consórcio e submetida a diferentes manejos de plantas daninhas, constatou-se que a braquiária produziu mais forragem nos tratamentos com ou sem capinas, em comparação com os tratados com herbicidas, exceto no consórcio com o híbrido duplo DKB 789, no qual o rendimento de forragem sem capina foi igual ao do tratamento com atrazine (Tabela 4). Os rendimentos da braquiária em consorciação com a variedade UFV M100 foram superiores aos observados na consorciação com os outros cultivares, nos manejos com capinas, sem capinas e com atrazine. No entanto, a aplicação de atrazine + nicosulfuron proporcionou maiores valores de matéria seca na consorciação com o híbrido duplo DKB 789, devido à ação do herbicida nicosulfuron sobre o crescimento inicial da braquiária, conforme relatado por Jakelaitis et al. (2005). 
Tabela 3 - Matéria seca da parte aérea da braquiária consorciada com diferentes cultivares de milho e épocas de avaliação

\begin{tabular}{|c|c|c|c|c|}
\hline \multirow{4}{*}{$\begin{array}{c}\text { Época de coleta } \\
\text { (dias após o plantio) }\end{array}$} & \multicolumn{4}{|c|}{ Braquiária em consorciação com milho } \\
\hline & \multicolumn{4}{|c|}{ Cultivares de milho } \\
\hline & $\begin{array}{l}\text { Variedade UFV } \\
\text { M100 }\end{array}$ & $\begin{array}{l}\text { Híbrido triplo DKB } \\
\qquad 455\end{array}$ & $\begin{array}{l}\text { Híbrido duplo DKB } \\
789\end{array}$ & $\begin{array}{c}\text { Híbrido simples } \\
\text { DKB } 390\end{array}$ \\
\hline & \multicolumn{4}{|c|}{ Matéria seca da parte aérea $\left(\mathrm{y}, \mathrm{kg} \mathrm{ha}^{-1}\right)$} \\
\hline 30 & $11 \mathrm{~A}^{\frac{1}{}}$ & $7 \mathrm{~A}$ & $8 \mathrm{~A}$ & $10 \mathrm{~A}$ \\
\hline 60 & $464 \mathrm{~A}$ & $459 \mathrm{~A}$ & $499 \mathrm{~A}$ & $432 \mathrm{~A}$ \\
\hline 90 & $2.832 \mathrm{~A}$ & $2.690 \mathrm{~A}$ & $2.684 \mathrm{~A}$ & $2.483 \mathrm{~A}$ \\
\hline 120 & $5.266 \mathrm{~A}$ & $4.599 \mathrm{~B}$ & $4.711 \mathrm{~B}$ & $4.419 \mathrm{~B}$ \\
\hline 150 & $6.973 \mathrm{~A}$ & $6.417 \mathrm{BC}$ & $6.219 \mathrm{C}$ & $5.842 \mathrm{BC}$ \\
\hline \multicolumn{5}{|c|}{ Equações de regressão e respectivos coeficientes de determinação } \\
\hline \multicolumn{2}{|c|}{ Braquiária em consorciação com UFV M100 } & \multicolumn{3}{|c|}{$\mathrm{y}=6991,4 /\left(1+145,6 \mathrm{e}^{24,8 \mathrm{t}}\right), \mathrm{R}^{2}=0,98$} \\
\hline \multicolumn{2}{|c|}{ Braquiária em consorciação com DKB 455} & \multicolumn{3}{|c|}{$y=6376,9 /\left(1+149,1 e^{26,5 t}\right), R^{2}=0,97$} \\
\hline \multicolumn{2}{|c|}{ Braquiária em consorciação com DKB 789} & \multicolumn{3}{|c|}{$y=6217,9 /\left(1+145,9 e^{25,8 t}\right), R^{2}=0,97$} \\
\hline \multicolumn{2}{|c|}{ Braquiária em consorciação com DKB 390} & \multicolumn{3}{|c|}{$\mathrm{y}=5845,5 /\left(1+145,8 \mathrm{e}^{25,5 \mathrm{t}}\right), \mathrm{R}^{2}=0,97$} \\
\hline
\end{tabular}

1/ Médias seguidas pela mesma letra, em cada linha, não diferem entre si a 5\% de probabilidade pelo teste de Tukey. Todos os parâmetros das equações de regressão são significativos a $5 \%$ de probabilidade pelo teste $\mathrm{t}$ de Student.

Tabela 4 - Matéria seca da parte aérea da braquiária, cultivada em monocultivo e em consorciação com cultivares de milho, com diferentes manejos das plantas daninhas

\begin{tabular}{|c|c|c|c|c|c|}
\hline \multirow{5}{*}{ Cultivares de milho } & \multicolumn{4}{|c|}{ Sistemas de cultivo } & \\
\hline & \multicolumn{4}{|c|}{ Braquiária em consorciação com milho } & \multirow[b]{3}{*}{$\begin{array}{c}\text { Braquiária em } \\
\text { monocultivo, } \\
\text { com capinas }\end{array}$} \\
\hline & \multicolumn{4}{|c|}{ Manejo de plantas daninhas } & \\
\hline & Com capinas & $\begin{array}{l}\text { Sem controle de } \\
\text { plantas daninhas }\end{array}$ & $\begin{array}{c}\text { Atrazine } \\
\left(1,5 \mathrm{~kg} \mathrm{ha}^{-1}\right)\end{array}$ & $\begin{array}{c}\text { Atrazine }+ \\
\text { nicosulfuron } \\
\left(1,5 \mathrm{~kg} \mathrm{ha}^{-1}+\right. \\
\left.8 \mathrm{~g} \mathrm{ha}^{-1}\right)\end{array}$ & \\
\hline & \multicolumn{4}{|c|}{ Rendimento de forragem (matéria seca da parte aérea, $\mathrm{kg} \mathrm{ha}^{-1}$ ) } & \\
\hline Variedade UFV M100 & $8.697 \mathrm{Ba}^{\frac{1}{1}}$ & $7.879 \mathrm{Ba}$ & $6.479 \mathrm{Ca}$ & $3.679 \mathrm{Db}$ & \multirow{4}{*}{$10.026 \mathrm{~A}$} \\
\hline Híbrido triplo DKB 455 & $7.750 \mathrm{Bb}$ & $6.709 \mathrm{Bb}$ & $5.458 \mathrm{Cb}$ & 4.037 Dab & \\
\hline Híbrido duplo DKB 789 & $7.522 \mathrm{Bb}$ & $6.058 \mathrm{Cc}$ & $5.113 \mathrm{CDb}$ & $4.272 \mathrm{Da}$ & \\
\hline Híbrido simples DKB 390 & $7.052 \mathrm{Bc}$ & $6.122 \mathrm{BCc}$ & $5.151 \mathrm{Cb}$ & $2.754 \mathrm{Dc}$ & \\
\hline
\end{tabular}

1/ Médias seguidas pela mesma letra maiúscula, em cada linha, e pela mesma letra minúscula, em cada coluna, não diferem entre si a $5 \%$ de probabilidade pelo teste de Tukey.

Houve efeito de cultivares (C), manejo de plantas daninhas $(\mathrm{M})$, épocas de avaliação do crescimento (E) e das interações $\mathrm{M}$ x E e M x C no crescimento do milho. Nas duas primeiras avaliações (30 e 60 DAP) não se constataram diferenças entre sistemas de cultivo no crescimento do milho (Tabela 5). No entanto, nas avaliações de crescimento feitas a partir dos 90 dias após o plantio, os cultivares de milho apresentaram maior crescimento no monocultivo do que nos consórcios, mesmo quando foram aplicados herbicidas ou realizadas capinas. A aplicação de atrazine + nicosulfuron mostrou os melhores resultados em relação aos demais manejos das plantas daninhas, embora não tenha sido suficiente para garantir o crescimento do milho igual ao do monocultivo. Esses resultados são contrários aos observados por Freitas et al. (2005), que relataram a eficiência da aplicação do atrazine + nicosulfuron para supressão do crescimento da forrageira e produção de 
milho-silagem. Essa divergência de resultados talvez possa ser explicada pela diferença entre os tipos de solo nas duas pesquisas. Na condição de solo ácido, como no caso do presente estudo, verificou-se menor desenvolvimento do milho e, por isso, menor competição com a braquiária. Segundo Guedes et al. (2009), a braquiária tem crescimento satisfatório mesmo em condições de maior acidez do solo, o que não é verdade para o milho.

Provavelmente, a baixa fertilidade natural da área experimental e a aplicação superficial do agrossilício usado para correção da acidez do solo causaram o menor crescimento do milho nos sistemas. Esse fato favoreceu a competição da forrageira com o milho e, consequentemente, o menor crescimento da cultura. De acordo com Felipe (2012), os atributos químicos do solo são alterados pela aplicação superficial do agrossilício, porém são necessários maiores períodos de tempo para que haja correção da acidez em profundidade.

Nas avaliações da matéria seca do milho realizadas aos 30, 60 e 90 DAP, não se observaram diferenças entre cultivares no consórcio com a braquiária (Tabela 6), exceto para o híbrido triplo DKB 455, que nessa época apresentou crescimento inferior ao dos demais cultivares. Entretanto, nas duas últimas avaliações, o híbrido simples DKB 390 mostrou valores superiores de matéria seca em comparação com os de outros cultivares. De modo geral, na consorciação milho-braquiária, o maior crescimento de um cultivar de milho corresponde a menor crescimento da braquiária e vice-versa (Tabela 2). Esses resultados são semelhantes aos encontrados por Petter et al. (2011) e Jakelaitis et al. (2006) para $U$. ruzizienses e $U$. brizantha.

Com relação à produtividade de grãos dos cultivares de milho, observou-se maior produção do híbrido simples DKB 390, quando comparado com o híbrido triplo DKB 455 (Tabela 7). A aplicação de atrazine+ nicosulfuron resultou em produtividade maior do milho, quando comparado aos demais métodos de controle, e semelhante à do monocultivo capinado, confirmando a eficiência do sistema. Portanto, a capacidade de adaptação ao consórcio depende do genótipo de milho usado, bem como do sistema de controle de plantas daninhas, fato esse constatado também por Freitas et al. (2008).

Tabela 5 - Matéria seca da parte aérea do milho em diferentes sistemas de cultivo e épocas de avaliação

\begin{tabular}{|c|c|c|c|c|c|}
\hline \multirow{4}{*}{$\begin{array}{c}\text { Época de coleta } \\
\text { (dias após o plantio) }\end{array}$} & \multicolumn{5}{|c|}{ Sistemas de cultivo } \\
\hline & \multirow[b]{2}{*}{$\begin{array}{c}\text { Milho em } \\
\text { monocultivo, } \\
\text { com capinas }\end{array}$} & \multicolumn{4}{|c|}{ Milho em consorciação com braquiária } \\
\hline & & $\begin{array}{c}\text { Atrazine }+ \\
\text { Nicosulfuron } \\
\left(1,5 \mathrm{~kg} \mathrm{ha}^{-1}+\right. \\
\left.8 \mathrm{~g} \mathrm{ha}^{-1}\right)\end{array}$ & $\begin{array}{c}\text { Atrazine } \\
\left(1,5 \mathrm{~kg} \mathrm{ha}^{-1}\right)\end{array}$ & $\begin{array}{c}\text { Sem controle } \\
\text { de plantas } \\
\text { daninhas }\end{array}$ & Com capinas \\
\hline & \multicolumn{5}{|c|}{ Matéria seca da parte aérea $\left(\mathrm{kg} \mathrm{ha}^{-1}\right)$} \\
\hline 30 & $33 \mathrm{~A}^{1 /}$ & $30 \mathrm{~A}$ & $33 \mathrm{~A}$ & $35 \mathrm{~A}$ & $33 \mathrm{~A}$ \\
\hline 60 & $815 \mathrm{~A}$ & $783 \mathrm{~A}$ & $980 \mathrm{~A}$ & $695 \mathrm{~A}$ & $658 \mathrm{~A}$ \\
\hline 90 & $7.667 \mathrm{~A}$ & $5.236 \mathrm{BC}$ & $3.700 \mathrm{BC}$ & $2.918 \mathrm{C}$ & $3.109 \mathrm{C}$ \\
\hline 120 & $13.007 \mathrm{~A}$ & $10.696 \mathrm{~B}$ & $6.847 \mathrm{C}$ & $6.729 \mathrm{C}$ & $6.609 \mathrm{C}$ \\
\hline 150 & $12.020 \mathrm{~A}$ & $9.299 \mathrm{~B}$ & $6.160 \mathrm{C}$ & $5.514 \mathrm{C}$ & $5.676 \mathrm{C}$ \\
\hline \multicolumn{6}{|c|}{ Equações de regressão e respectivos coeficientes de determinação } \\
\hline \multicolumn{3}{|c|}{ Milho em monocultivo - com capinas } & \multicolumn{3}{|c|}{$\mathrm{y}=14280,0 /\left(1+130,8 \mathrm{e}^{21,9 t}\right), \mathrm{R}^{2}=0,96$} \\
\hline \multicolumn{3}{|c|}{ Milho em consorciação - com atrazine + nicosulfuron } & \multicolumn{3}{|c|}{$\mathrm{y}=11583,1 /\left(1+130,4 \mathrm{e}^{20,2 t}\right), \mathrm{R}^{2}=0,99$} \\
\hline \multicolumn{3}{|c|}{ Milho em consorciação - atrazine } & \multicolumn{3}{|c|}{$\mathrm{y}=7371,8 /\left(1+130,6 \mathrm{e}^{22,2 \mathrm{t}}\right), \mathrm{R}^{2}=0,99$} \\
\hline \multicolumn{3}{|c|}{ Milho em consorciação - sem controle de daninhas } & \multicolumn{3}{|c|}{$y=7183,3 /\left(1+129,7 e^{19,3 t}\right), R^{2}=0,99$} \\
\hline \multicolumn{3}{|c|}{ Milho em consorciação - com capinas } & \multicolumn{3}{|c|}{$\mathrm{y}=7108,2 /\left(1+130,4 \mathrm{e}^{20,2 \mathrm{t}}\right), \mathrm{R}^{2}=0,99$} \\
\hline \multicolumn{6}{|c|}{ Coeficiente de variação experimental $(\mathrm{CV})_{\text {parcelas }}=47,1 \% ; \mathrm{CV}_{\text {subparcelas }}=36,5 \%$. } \\
\hline
\end{tabular}


Tabela 6 - Matéria seca da parte aérea de cultivares de milho consorciados com braquiária, em função da idade da planta

\begin{tabular}{|c|c|c|c|c|}
\hline \multirow{4}{*}{$\begin{array}{l}\text { Época de coleta } \\
\text { (dias após o } \\
\text { plantio) }\end{array}$} & \multicolumn{4}{|c|}{ Milho em consorciação com braquiária } \\
\hline & \multicolumn{4}{|c|}{ Cultivares de milho } \\
\hline & $\begin{array}{l}\text { Híbrido simples DKB } \\
390\end{array}$ & $\begin{array}{c}\text { Híbrido duplo DKB } \\
789\end{array}$ & $\begin{array}{l}\text { Híbrido triplo DKB } \\
455\end{array}$ & Variedade UFV M100 \\
\hline & \multicolumn{4}{|c|}{ Matéria seca da parte aérea $\left(\mathrm{y}, \mathrm{kg} \mathrm{ha}^{-1}\right)$} \\
\hline 30 & $72 \mathrm{~A}^{\underline{1 /}}$ & $14 \mathrm{~A}$ & $25 \mathrm{~A}$ & $20 \mathrm{~A}$ \\
\hline 60 & $1602 \mathrm{~A}$ & $451 \mathrm{~A}$ & $602 \mathrm{~A}$ & $490 \mathrm{~A}$ \\
\hline 90 & $5656 \mathrm{~A}$ & $4670 \mathrm{~A}$ & $2506 \mathrm{~B}$ & $5272 \mathrm{~A}$ \\
\hline 120 & $11409 \mathrm{~A}$ & $8196 \mathrm{~B}$ & $8400 \mathrm{~B}$ & $7106 \mathrm{~B}$ \\
\hline 150 & $10535 \mathrm{~A}$ & $6280 \mathrm{~B}$ & $7278 \mathrm{~B}$ & $6280 \mathrm{~B}$ \\
\hline Altura de plantas & $122 \mathrm{~A}$ & $108 \mathrm{~B}$ & $114 \mathrm{AB}$ & $122 \mathrm{~A}$ \\
\hline \multicolumn{5}{|c|}{ Equações de regressão e respectivos coeficientes de determinação } \\
\hline \multicolumn{3}{|c|}{ Híbrido simples DKB 390 em consórcio com braquiária } & \multicolumn{2}{|c|}{$\mathrm{y}=12391,0 /\left(1+132,0 \mathrm{e}^{21,8 \mathrm{t}}\right), \mathrm{R}^{2}=0,99$} \\
\hline \multicolumn{3}{|c|}{ Híbrido duplo DKB 789 em consórcio com braquiária } & \multicolumn{2}{|c|}{$\mathrm{y}=8611,9 /\left(1+126,2 \mathrm{e}^{20,1 \mathrm{t}}\right), \mathrm{R}^{2}=0,96$} \\
\hline \multicolumn{3}{|c|}{ Híbrido triplo DKB 455 em consórcio com braquiária } & \multicolumn{2}{|c|}{$\mathrm{y}=9604,2 /\left(1+132,3 \mathrm{e}^{16,5 t}\right), \mathrm{R}^{2}=0,99$} \\
\hline \multicolumn{3}{|c|}{ Variedade UFV M100 em consórcio com braquiária } & \multicolumn{2}{|c|}{$\mathrm{y}=7760,90 /\left(1+126,8 \mathrm{e}^{22,9 t}\right), \mathrm{R}^{2}=0,89$} \\
\hline
\end{tabular}

${ }^{1 /}$ Médias seguidas pela mesma letra, em cada linha, não diferem entre si a $5 \%$ de probabilidade pelo teste de Tukey. Todos os parâmetros das equações de regressão são significativos a $5 \%$ de probabilidade pelo teste $t$ de Student.

Tabela 7 - Produtividade de grãos de milho em função do cultivar e do sistema de cultivo

\begin{tabular}{|c|c|c|c|c|c|}
\hline \multicolumn{6}{|c|}{ Produtividade de grãos de milho $\left(\mathrm{kg} \mathrm{ha}^{-1}\right)$} \\
\hline \multicolumn{6}{|c|}{ Cultivares de milho } \\
\hline Híbrido simples DKB 390 & \multicolumn{2}{|c|}{ Híbrido duplo DKB 789} & \multicolumn{2}{|c|}{ Híbrido triplo DKB 455} & Variedade UFV M100 \\
\hline $5.063 \mathrm{~A}^{1 /}$ & \multicolumn{2}{|c|}{$4.161 \mathrm{AB}$} & \multicolumn{2}{|c|}{$3.250 \mathrm{~B}$} & $4.179 \mathrm{AB}$ \\
\hline \multicolumn{6}{|c|}{ Sistemas de cultivo } \\
\hline $\begin{array}{l}\text { Milho em } \\
\text { monocultivo } \\
\text { com capinas }\end{array}$ & $\begin{array}{c}\text { Atrazine }+ \\
\text { nicosulfuron } \\
\left(1,5 \mathrm{~kg} \mathrm{ha}^{-1}+8 \mathrm{~g} \mathrm{ha}^{-1}\right) \\
\end{array}$ & \multicolumn{2}{|c|}{$\begin{array}{c}\text { Atrazine } \\
\left(1,5 \mathrm{~kg} \mathrm{ha}^{-1}\right)\end{array}$} & $\begin{array}{l}\text { Sem controle de } \\
\text { plantas daninhas }\end{array}$ & Com capinas \\
\hline $5.235 \mathrm{~A}$ & $5.006 \mathrm{~A}$ & \multicolumn{2}{|c|}{$3.291 \mathrm{~B}$} & $3.689 \mathrm{~B}$ & $3.291 \mathrm{~B}$ \\
\hline
\end{tabular}

1/ Médias seguidas pela mesma letra, em cada linha, não diferem entre si a $5 \%$ de probabilidade pelo teste de Tukey.

Conclui-se que os monocultivos da braquiária e do milho propiciaram maiores crescimento e rendimento do que os sistemas consorciados, quando não foi adotada nenhuma medida de controle das plantas daninhas. A aplicação de atrazine + nicosulfuron, no consórcio, possibilita rendimento de grãos de milho similar ao obtido no monocultivo. Os híbridos de milho mostraram-se mais competitivos com a braquiária do que a variedade; o maior rendimento de grãos foi obtido com o híbrido simples DKB 390, e o menor, com o híbrido triplo DKB 455. A interferência de
$U$. brizantha no milho, quando cultivados em consórcio, depende das práticas de manejo de plantas daninhas adotadas e do cultivar de milho plantado.

\section{LITERATURA CITADA}

ANDERSON, D. D. et al. Mechanism of primisulfuron resistance in sathercane (Sorghum bicolor) biotype.

Weed Sci., v.46, n. 1, p. 158-162, 1998.

BAYER, C. et al. Organic matter storage in a sandy clay loam Acrisol affected by tillage and cropping systems in southern Brazil. Soil Tillage Res., v. 54, n. 1, p. 101-109, 2000. 
CARVALHO, F. P. et al. Alocação de matéria seca e capacidade competitiva de cultivares de milho com plantas daninhas. Planta Daninha, v.29, n. 2, p. 373-382, 2011.

CIOTTA, M. N. et al. Manejo da calagem e os componentes da acidez de Latossolo Bruno em plantio direto. R. Bras. Ci. Solo, v. 28, n. 2, p. 317-326, 2004.

CHIKOYE, D. et al. Response of corn genotypes to weed interference and nitrogen in Nigeria. Weed Sci., v. 56, n. 3, p. 424-433, 2008.

FELIPE, R. S. Alterações nos atributos químicos do solo com aplicação de agrossilício no consórcio milho e braquiária. Dissertação (Mestrado em Fitotecnia) Universidade Federal de Viçosa, Viçosa, MG, 2012.

FREITAS, F. C. L. et al. Comportamento de cultivares de milho no consórcio com Brachiaria brizantha na presença e ausência de foramsulfuron + iodosulfuron-methyl para o manejo da forrageira. Planta Daninha, v. 26, n. 1, p. 215-221, 2008.

FREITAS, F. C. L. et al. Formação de pastagem via consórcio de Brachiaria brizantha com o milho para silagem no sistema plantio direto. Planta Daninha, v. 23, n. 1, p. 49-58, 2005.

GUEDES, E. M. S. et al. Fosfato natural de arad e calagem e o crescimento de Brachiaria brizanta em latossolo amarelo sob pastagem degradada na Amazônia. R. Ci. Agr., v. 52, n. 2, p. 117-129, 2009.

JAKELAITIS, A. et al. Efeitos de herbicidas no controle de plantas daninhas, crescimento e produção de milho e Brachiaria brizantha em consórcio. Pesq. Agropec. Trop., v. 36, n. 1, p. 53-60, 2006.
JAKELAITIS, A. et al. Influência de herbicidas e de sistemas de semeadura de Brachiaria brizantha consorciada com milho. Planta Daninha, v. 2, n. 1, p. 59-67, 2005.

MESQUITA, E. E. et al. Estabelecimento de pastagem consorciada com aplicação de calcário, fósforo e gesso. $\mathbf{C i}$. Agrotecnol., v. 28, n. 2, p. 428-436, 2004.

NASCIMENTO, M. C. et al. Uso de imagens do sensor ASTER na identificação de níveis de degradação em pastagens. R. Bras. Eng. Agríc. Amb., v. 10, n. 1, p. 196-202, 2006.

PACIULLO, D. S. C. et al. The growth dynamics in Urochloa species according to nitrogen dose and shade. R. Bras. Zootec., v. 40, n. 2, p. 270-276, 2011.

PETTER, F. A. et al. Seletividade de herbicidas à cultura do milho e ao capim-braquiária cultivadas no sistema de integração lavoura-pecuária. Semina: Ci. Agr., v. 32, n. 3, p. 855-864, 2011.

PIERCE, F. J. et al. Periodic plowing effects on soil properties in a no-till farming system. Soil Sci. Soc. Am. J., v. 58, n. 6 , p. 1782-1787, 1994.

PORTES, T. A. et al. Análise do crescimento de uma cultivar de braquiária em cultivo solteiro e consorciado com cereais. Pesq. Agropec. Bras., v. 35, n. 7, p. 1349-1358, 2000.

SCIENTIFIC, J. Table curve: curve fitting software. Corte Madera: 1991. $280 \mathrm{p}$.

VITOR, C. M. T. et al. Rendimento e composição química do capim-braquiária introduzido em pastagem degradada de capimgordura. R. Bras. Zootec., v. 37, n. 2, p. 2107-2114, 2008. 